\title{
PENGEMBANGAN
}

\section{KOMPETENSI PROFESIONAL BERKELANJUTAN DOSEN VOKASI PADA PENDIDIKAN VOKASIONAL DI LAMPUNG}

\author{
Sugiyanto \\ Fakultas Teknik Universitas Lampung \\ soegijanto_mesin@yahoo.com \\ Slamet PH \\ Fakultas Teknik, Unversitas Negeri Yogyakarta \\ slametph.@yahoo.com \\ Sugiyono \\ Fakultas Teknik, Universitas Negeri Yogyakarta \\ sugiyono_1953@yahoo.com \\ Abstrak
}

\begin{abstract}
Tujuan penelitian ini adalah menghasilkan model pengembangan kompetensi profesional berkelanjutan bagi setiap dosen vokasi (PKPB-DV) agar memiliki kompetensi untuk dapat menjalankan tugas pokok dan fungsinya. Metode penelitian dan pengembangan digunakan untuk menjawab pertanyaan penelitian, dengan subjek penelitian pegawai, pimpinan perguruan tinggi, dosen yang ditentukan secara purposif. Data dikumpulkan dengan pedoman wawancara dan angket serta dianalisis secara deskripsi kualitatif. Hasil penelitian menunjukkan bahwa model pengembangan kompetensi berkelanjutan memiliki empat unsur yaitu: (1) perencanaan berisi analisis karakter dosen vokasi, analisis kebutuhan dosen vokasi, pemilihan intervensi sarana, prasarana dan biaya, (2) pengorganisasian berisi mekanisme PKPB-DV, susunan organisasi mencakup keterlibatan individu dan tugas lembaga, koordinasi kegiatan mencakup kerjasama research danpenugasan oleh lembaga, (3) pelaksanaan meliputi tempat PKPB-DV, waktu pelaksanaan $P K P B-D V$, pemberian intervensi, pemberian bimbingan dan motivasi, dan (4) pengendalian yang berisi standar $P K P B-D V$.
\end{abstract}

Kata kunci: model pengembangan, kompetensi professional berkelanjutan, dosen vokasi

\section{CONTINUING PROFESSIONAL COMPETENCE DEVELOPMENT OF VOCATION LECTURERS ON VOCATIONAL EDUCATION IN LAMPUNG}

\begin{abstract}
This study aims to produce a model of continuing professional competence development of vocational lecturer (CPCD-VL) to have a competence to do their duties. The research and development methods are used to answer research questions with research participants consisting of administration staffs, university leaders, and lecturers that are determined purposively. Data were collected by interviews and questionnaires and analyzed by qualitative description. Results show that the model of continuing professional competence development has three elements, namely: (1) planning, an analysis of the character of vocational lecturers; needs analysis of vocation lecturer, and planning of the facilities, infrastructure and costs, (2) organization provides a mechanism of $C P C D$-VL, the organizational structure includes individual engagement and task organization, coordination of the activities include collaboration research and assignment, (3) implementation including $C P C D-V L$, the execution time of $C P C D-V L$, providing interventions, providing a guidance and motivation, and (4) control containing the standard of CPCD-VL.
\end{abstract}

Keywords: development model, continuing professional competency, vocational lecturer 


\section{PENDAHULUAN}

Tenaga dosen dalam pendidikan vokasional dituntut memiliki kompetensi profesional yang bersifat khusus agar output yang dihasilkan oleh lembaga pendidikan dapat menjadi outcome yang bermanfaat bagi masyarakat (Hoekstra \& Crocker, 2015) Menurut Wenrich \& Wenrich $(1974$, p. 36) pendidikan vokasional adalah "the total process of education aimed at developing competencies needed function effectively in an occupation or group of occupations". Pendidikan vokasional sebagai wadah pengembangan kompetensi sesuai dengan kebutuhan seseorang, dengan demikian pendidikan vokasional akan tepat sasaran dan sesuai dengan apa yang diperlukan di dunia kerja. Pendidikan vokasional sebagai pendidikan yang bersifat khusus karena dikembangkan atas dasar kebutuhan seseorang atas pekerjaan tertentu, dengan demikian jenis dan jenjang pekerjaan yang disiapkan oleh lembaga pendidikan vokasional yang satu dengan yang lain akan berbeda. Pendidikan vokasional selain bertujuan untuk mengembangkan hard skills, juga berorientasi pada soft skills, pendidikan nilai dan sikap (Wenrich \& Wenrich, 1974, p. 38).

Salah satu kunci sukses pendidikan tinggi adalah kompetensi yang dimiliki dosen. Dosen adalah salah satu komponen esensial dalam suatu sistem pendidikan di perguruan tinggi. Pentingnya peningkatan kompetensi profesional berkelanjutan dosen vokasi belum sepenuhnya disadari oleh dosen dan pemimpin di lembaga perguruan tinggi vokasi. Kompetensi profesional dosen mencakup tiga bidang yang sering disebut Tridharma Perguruan Tinggi. Dharma pertama adalah pendidikan dan pengajaran, dharma kedua penelitian dan dharma ketiga pengabdian kepada masyarakat, dan dosen juga masih dituntut untuk memiliki kegiatan penunjang untuk menyempurnakan ketiga kegiatan tersebut. Dengan demikian dosen yang memiliki kompetensi profesionaldapat dipastikan juga memiliki kompetensi sosial, kepribadian dan pedagogik.

Beberapa perguruan tinggi belum memiliki sumber daya manusia yang memiliki kompetensi mengelola data dosen mulai dari data personal sampai kepada data kinerja dan prestasi yang sudah diraih dosen. Hal ini terbukti setiap awal tahun akademik dan awal semester, semua dosen diminta mengirim data/curriculum vitae (CV), yang akan digunakan untuk keperluan pencairan tunjangan sertifikasi dosen. Hal ini tidak akan terjadi jika networking di perguruan tinggi tertata dengan rapi antarlembaga dengan fakultas, jurusan dan program studi.

Pengembangan kompetensi profesional berkelanjutan bagi dosen vokasi, sangat diperlukan untuk abad ke-21, ketika kehidupan abad ke-21 ditentukan oleh pengetahuan dan pelayanan (service) atau dikenal dengan knowledge based economy. Hal ini sesuai dengan penelitian yang dilakukan oleh Malmqvist, Gunnarsoon, \& Vigild (2008), Hegde (2013), Bolam (2006), dan Jackson (2011) yang menyatakan bahwa "Continuing professional development (CPD)" merupakan elemen penting dalam strategi belajar sepanjang hayat.

Dosen yang memiliki kompetensi profesional berkelanjutan akan dapat menjadikan dirinya manusia yang survive, yaitu manusia yang mampu berpikir kritis dan berkemauan untuk bekerja keras, kreatif, mampu menciptakan solusi baru untuk permasalahan lama, menemukan prinsip baru dan penemuan baru, menciptakan cara baru untuk mengomunikasikan gagasan baru, menemukan cara kreatif untuk mengatur proses yang kompleks. Manusia abad ke-21 harus mampu kerja sama kelompok untuk memecahkan masalah, berkomunikasi efektif, dan memiliki keterampilan berpikir tingkat tinggi. Untuk itu, mahasiswa tidak boleh hanya mengandalkan pembelajaran di kampus, tetapi dituntut menjadi pembelajar mandiri. Hal ini menjadi tugas dosen pada pendidikan vokasional.

Selain itu, seorang dosen mampu menerapkan teori andragogi; bagaimana orang tua belajar, ilmu tentang cara membimbing orang dewasa dalam proses belajar, yang merupakan seni dan ilmu yang membantu orang dewasa untuk belajar (Knowles, 1970; Srinivasan, 1977, p. 121). Pembelajaran dalam upaya menerapkan model peserta didik dewasa dapat diarahkan ke dalam berbagai bentuk kegiatan belajar sesuai dengan kebutuhannya, kebutuhan sumber, dan bahan belajar, seperti group discusion, team designing, role playing, simulations, skill practice sessions (Inggalls, 1973, p. 22; Knowles, 1970, p. 87; UNESCO, 1988, p. 71). 
Orang dewasa memiliki kemampuan membaca, menulis, menghitung dan menguasai kemampuan verbal dan kecakapan mengambil keputusan yang relevan dengan kebutuhan pribadi dan tuntutan sosialnya. Mereka merancang dan menetapkan minat dan kebutuhan belajarnya, mendiagnosis kebutuhannya sesuai tuntutan hidupnya dan lainlainnya. Pembelajaran dapat bertindak sebagai narasumber, pengarah, pembimbing, pemberi fasilitas, atau teman belajar (resource person, guide, helper, facilitator or partner for the learners) (Inggalls, 1973; Knowles, 1970, p. 88; UNESCO, 1988, p. 11; Saraka, 2001, p. $65)$.

Di dalam teori heutagogi, seorang dosen juga mampu menyediakan kerangka kerja bagi pembelajaran yang menempatkan orang dewasa yang bertanggung jawab untuk lebih maju. Sebagaimana dinyatakan oleh Kenyon \& Hase (2010, p. 165), bahwa heutagogi adalah ilmu belajar mandiri yang ditentukan oleh diri pembelajar sendiri, sebagai aktivitas kompleks yang membutuhkan perubahan yang meliputi keterampilan dan pengetahuan.

Oleh karena itu, pentingnya penelitian ini untuk mengembangkan dan menghasilkan model baru dalam pengembangan kompetensi professional berkelanjutan bagi dosen vokasi agar memiliki kompetensi untuk menjalankan tugas pokok dan fungsinya. Model baru merupakan pengembangan dan perbaikan program pengembangan kompetensi profesional berkelanjutan yang sudah ada. Model baru ini merupakan pedoman bagi setiap dosen vokasi agar lebih cepat dan berdaya dalam meningkatkan kemampuan kerja (kompetensi) baik pengetahuan (knowledge), keterampilan (skill), dan kemampuan (abilities) berkembang sesuai dengan tugas pokok dan fungsinya.

\section{METODE PENELITIAN}

Penelitian menggunakan metode penelitian research and development $(\mathrm{R} \& \mathrm{D})$, untuk menghasilkan produk tertentu, dan menguji keefektifan produk (Sugiyono, 2010, p. 407). Model pengembangan dalam penelitian ini merujuk pada siklus Research and Development $(R \& D)$ meliputi penentuan produk yang akan dikembangkan (define), membuat desain produk (design), peragaan (demonstrate), pengembangan (develop) dan penyajian (delivery). Tahapan pengembangan penelitian ini secara garis besar dapat dikategorikan menjadi tiga, yaitu: (1) tahap prapengembangan (research), (2) tahap pengembangan, dan (3) tahap penerapan model.

Penelitian dilaksankan di perguruan tinggi vokasi di Provinsi Lampung pada tahun 2015. Subjek penelitian meliputi dosen sebanyak 10 orang, pimpinan perguruan tinggi (PT)/Tim Penjaminan Mutu Akademik (TPJA) 6 orang, dan bagian kepegawaian 6 orang. Jumlah keseluruhan subjek dari FGD I, II dan III adalah 30 orang. Subjek dari dosen diambil secara purposif dari jumlah dosen vokasi yang tersebar di seluruh perguruan tinggi di Lampung sekitar 635 orang, dengan rincian dosen dengan Jabatan Akademik Asis-ten Ahli 3 orang, dosen dengan Jabatan Akademik Lektor 4 orang, dosen dengan Jabatan Akademik Lektor Kepala 3 orang, pimpinan PT/TPJA 6 orang, dan Bagian Kepegawaian 6 orang. Subjek penelitian ditentukan secara purposif dengan teknik snowball.

Tahap penelitian melalui tiga tahap yaitu prapengembangan model (research), pengembangan model dan penerapan model, yang dijabarkan secara skematik pada Gambar 1. Tahap prapengembangan dilakukan dengan mengumpulkan informasi mengenai PKPBDV, yang sasarannya adalah peningkatan kompetensi profesional berkelanjutan untuk dosen vokasi di Lampung. Kajian literatur hasil penelitian yang relevan juga dilakukan. Selain itu, upaya pembinaan dosen vokasi oleh pimpinan PT/Kepegawaian pada pendidikan vokasi di Lampung yang sudah dilaksanakan selama ini juga diamati. Pengumpulan data dilakukan melalui observasi langsung dan wawancara terhadap dosen, kepala bagian kepegawaian dan pimpinan PT/TPJA. Penentuan responden dilakukan secara purposif dengan teknik snowball, jika responden yang dituju tidak ditemukan pada saat wawancara dan observasi maka dicari responden lain untuk menggantikannya dengan memperhatikan tujuan dari wawancara dan observasi tersebut. 


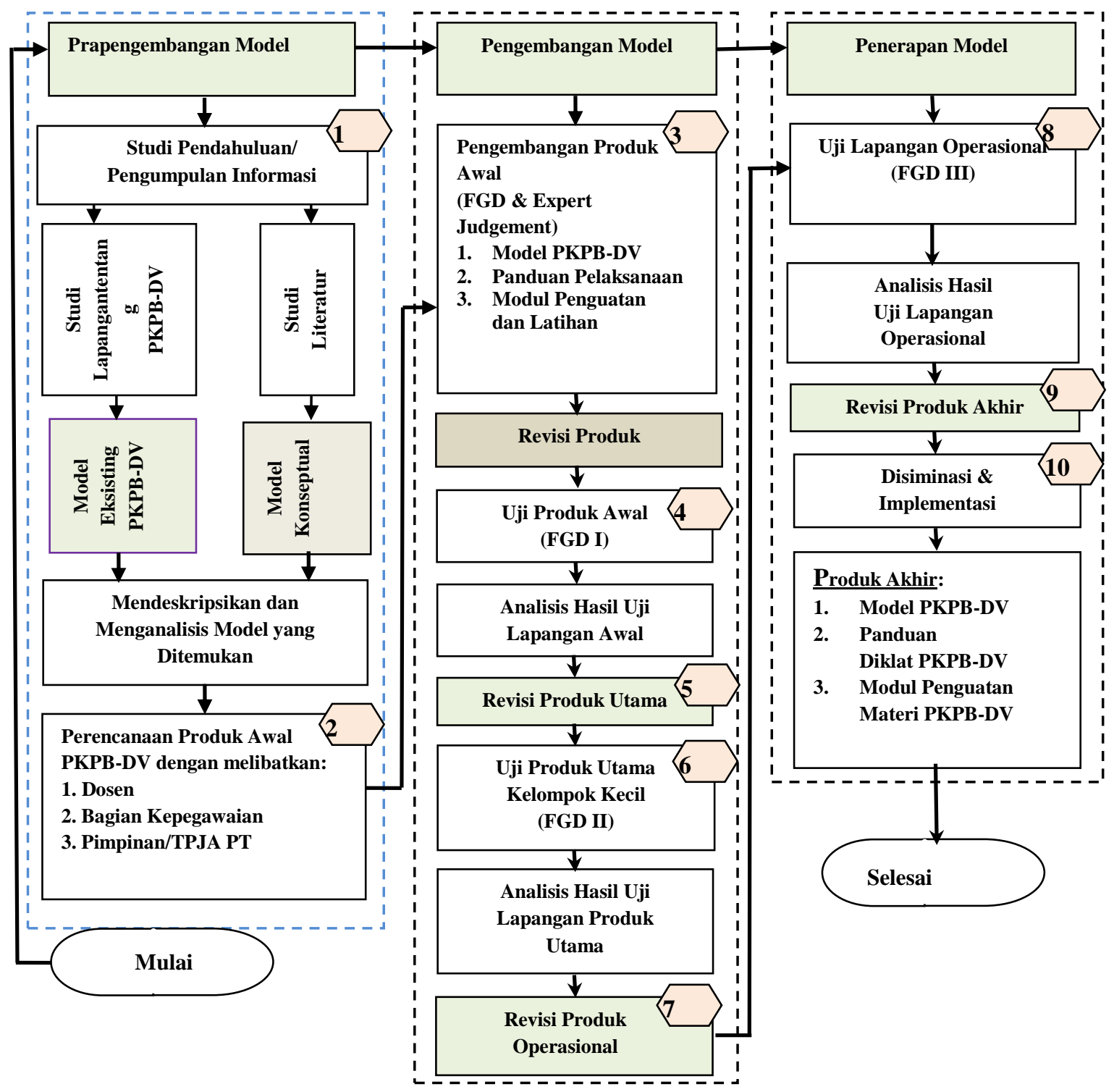

Gambar 1. Prosedur Pengembangan Model: Pengembangan Kompetensi Profesional Berkelanjutan Dosen Vokasi (PKPB-DV)

Pengumpulan data juga dilakukan melalui identifikasi terhadap temuan-temuan hasil penelitian terdahulu yang relevan, dan menelaah berbagai konsep serta teori yang berkaitan dengan pengembangan kompetensi dosen. Selain itu, juga dikaji mengenai ruang lingkup produk PKPB-DV, kondisi pendukung penggunaan model, keunggulan dan kekurangan model, dan mengidentifikasi keunggulan dan keterbatasan produk (model) yang dikembangkan. Kegiatan-kegiatan tersebut berfungsi sebagai analisis kebutuhan yang dipakai sebagai landasan pengembangan model PKPB-DV yang efektif untuk peningkatan kompetensi profesional dosen secara berkelanjutan. Hal ini akan menghasilkan model konseptual PKPB-DV.
Studi lapangan dilakukan untuk mendapatkan model existing yang ditujukan kepada; pimpinan perguruan tinggi/tim penjamin mutu, bagian kepegawaian dan para dosen vokasi. Bersama model konseptual, model ini dikaitkan dengan karakter dosen vokasi dan tuntutan kebijakan yaitu empat kompetensi dosen (Depdiknas, 2005) antara lain; kompetensi kepribadian, kompetensi sosial, kompetensi profesional dan kompetensi pedagogik serta kegiatan Tri Dharma perguruan tinggi yang mencakup pendidikan/pengajaran, penelitian, pengabdian kepada masyarakat serta unsur penunjang. Kemudian bersama pimpinan/ tim penjamin mutu perguruan tinggi, bagian kepegawaian dan dosen, perencanaan produk awal model PKPB-DV dikembangkan. 
Pada tahap pengembangan dirumuskan arah pengembangan model PKPB-DV berdasarkan kebutuhan dosen vokasi. Langkahlangkah dalam tahapan ini meliputi penyesuaian konsep, struktur produk/model PKPB$\mathrm{DV}$, komponen dan isi komponen, pembuatan rancangan model, dan penampilan model. Langkah-langkah tersebut ditempuh ditentukan lebih dahulu sasaran PKPB-DV,

Sebelum konstruk ditentukan batasan aspek-aspek yang ada di dalamnya. Sasaran PKPB-DV adalah peningkatan kompetensi profesional dosen vokasi secara berkelanjutan. PKPB-DV sebagai suatu proses pembinaan karier dosen vokasi, yang terdiri dari dimensi pengetahuan/kompetensi, sikap profesional dan keterampilan untuk menjadi dosen profesional.

Selanjutnya model unggul yang diperoleh didiskusikan dalam Forum Group Discussion (FGD) yang melibatkan pakar dan pengguna yaitu pimpinan perguruan tinggi dan/atau tim penjamin mutu, bagian kepegawaian, dan dosen. Semua ini bertujuan untuk mendapatkan informasi secara komprehensif mengenai model PKPB-DV. Rancangan model PKPB-DV didiskusikan kepada dosen, bagian kepegawaian dan pakar yang memiliki keahlian relevan dengan pendidikan vokasi. Pelibatan pakar, bagian kepegawaian dan TPJA/pimpinan PT dilakukan dengan FGD.

Pada tahap pengembangan model, pembuatan rancangan model PKPB-DV yang telah dihasilkan merupakan model atau prototype semi sempurna. Oleh karena itu, model PKPB-DV yang dihasilkan dari tahap ini akan diuji dan dikembangkan kembali melalui FGD I, II dan III. FGD I merupakan "uji satu-satu" yang melibatkan satu orang dosen, satu orang pimpinan PT/TPJA dan satu orang dari bagian kepegawaian. Hasil masukan dari FGD I direvisi dan kemudian diuji melalui FGD II.Tahap FGD II melibatkan kelompok kecil yang terdiri dari tiga orang dosen, tiga orang pegawai dan tiga orang pimpinan PT/TPJA. Berdasarkan masukan dari hasil uji FGD II, kemudian dilakukan uji FGD III. Tahap uji FGD III merupakan kelompok besar dengan melibatkan enam belas orang yang berasal dari enam orang dosen, enam orang pimpinan PT/TPJA, dan empat orang dari bagian kepegawaian. Sasaran kegiatan pada tahap uji FGD III adalah untuk memantapkan dan memvalidasi model. Data pengembangan kompetensi profesional berkelanjutan bagi dosen vokasi dilakukan melalui FGD. Data hasil FGD digunakan untuk menyusun desain model unggul.

Komponen model dinilai oleh pakar menggunakan skala penilaian dengan 4 pilihan jawaban yang sesuai dengan isi pertanyaan, yaitu: Sangat Penting (SP), Penting (P), Kurang Penting (KP) dan Tidak Penting (TP). Dari penilaian tersebut kemudian dilihat persentase pada setiap skor kemudian diinterpretasikan kelayakannya, rumus persentase yang digunakan menurut Sudijono (2009, p. 43) adalah $\mathrm{P}=f / N \times 100 \%$, dimana $f=$ frekuensi hasil penilaian, $N=$ number of case (jumlah frekuensi keseluruhan), dan $\mathrm{P}=$ angka persentase. Penentuan kriteria pencapaian hasil persentase menggunakan pendapat Sudijono (2009, p. 45) yaitu: $80 \%-100 \%=$ Sangat Penting (SP), $70 \%-79 \%=$ Penting (P), 60\% $-69 \%=$ Kurang Penting (KP), dan $<60 \%=$ Tidak Penting (TP).

\section{HASIL PENELITIAN DAN PEMBAHASAN}

Hasil studi tahap prapengembangan dituangkan dalam konsep kerangka pengembangan PKPB-DV. Langkah selanjutnya, konsep tersebut didiskusikan dalam forum FGD dengan pakar yaitu: dosen, pimpinan PT/ TPJA dan kepegawaian. Pada hakikatnya pengembangan PKPB-DV dilaksanakan untuk memperbaiki kelemahan-kelemahan pada model yang sudah diterapkan. Perbaikan-perbaikan yang ada harus dilakukan oleh pihak perguruan tinggi vokasional, yaitu: meliputi tahapan-tahapan perencanaan, pengorganisasian, pelaksanaan, dan pengendalian dalam rangka menerapkan model unggul PKPB-DV.

Model existing diperoleh dari studi lapangan dan model konseptual diperoleh dari studi literatur, sebagaimana ditampilkan pada Gambar 2. Kedua model diperbaiki dan disesuaikan dengan karakter dosen vokasi dan pengelola SDM yang meliputi: perencanaan, pengorganisasian, pelaksanaan dan pengendalian. Kemudian kedua model disempurnakan menjadi model hipotetik PKPB-DV sebagaimana ditampilkan pada Gambar 3.

Proses analisis pada tahap prapengembangan menghasilkan deskripsi model, yang dijadikan dasar pengembangan model PKPBDV dengan melibatkan pakar, yaitu: dosen vokasi, bagian kepegawaian, dan pimpinan PT/TPJA pendidikan tinggi. 


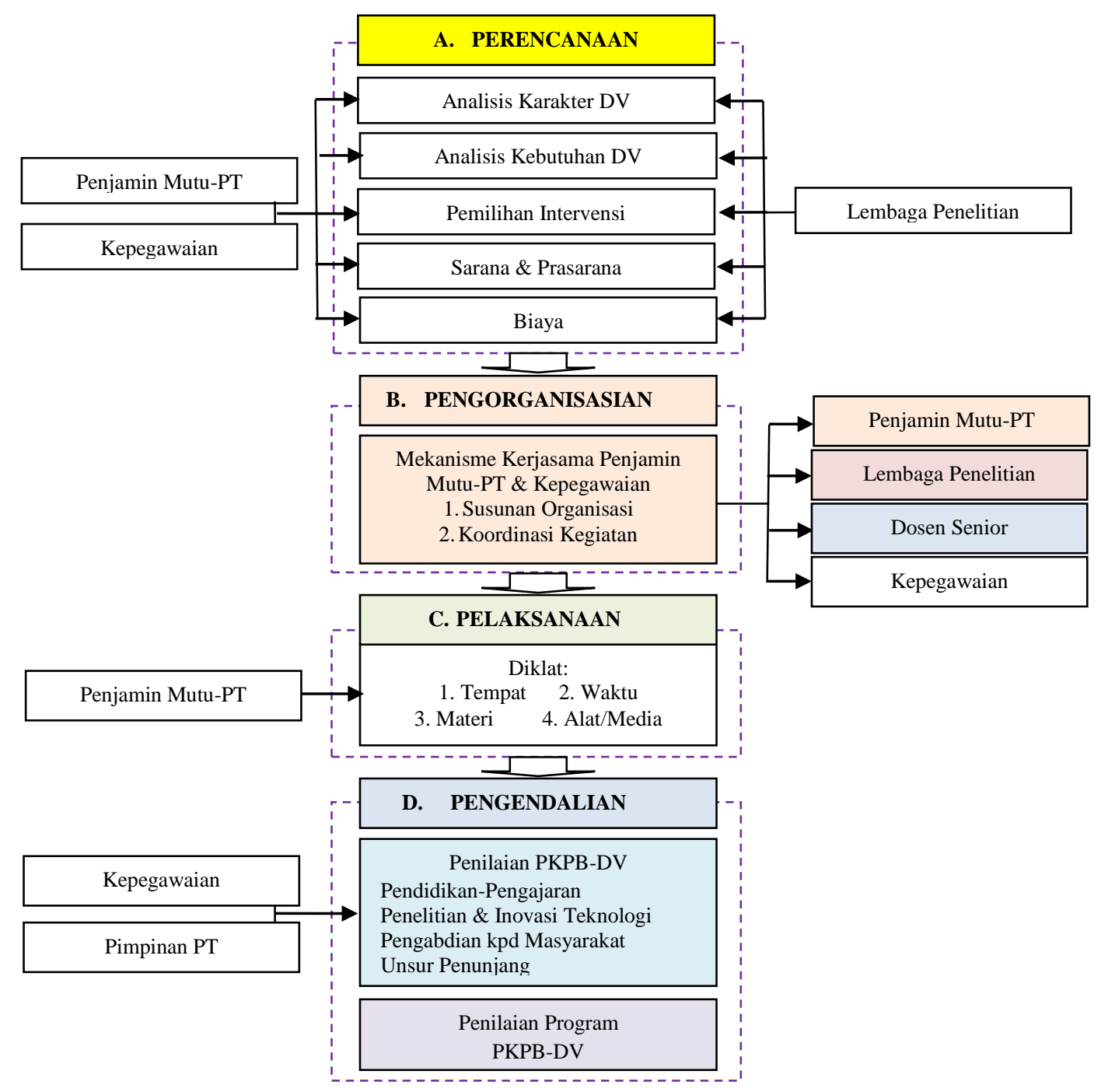

Gambar 2. Model Konseptual PKPB-DV

Selanjutnya, kerangka model dan instrumen yang dikembangkan merupakan hasil pemikiran peserta FGD. Peserta FGD menyampaikan gagasannya secara terbuka dan menyepakati hasil FGD. Pelaksanaan FGD bertujuan untuk mendiskusikan struktur model dan komponen model PKPB-DV. Penulis mempersiapkan draf dan model. Draf yang belum lengkap dimintakan saran, masukan, dan analisis dari peserta FGD. FGD II melibatkan 6 orang pakar, yaitu 2 orang dosen vokasi, 2 orang pimpinan perguruan tinggi, dan 2 orang kepegawaian perguruan tinggi yang berasal dari Perguruan Tinggi yang memiliki program studi (PS) vokasional di Provinsi Lampung. Selain itu, juga dikonsultasikan de- ngan beberapa ahli pendidikan vokasional sebagai expert judgement.

\section{Ringkasan hasil pelaksanaan FGD terhadap model PKPB-DV sebagai berikut:}

\section{Model PKPB-DV}

Model PKPB-DVmengandung struktur/ elemen, komponen, dan panduan diklat. Struktur/elemen model penyelenggaraan PKPB-DV meliputi: dosen vokasi dan pengelola. Di antara kedua struktur/elemen terdapat kegiatan-kegiatan: perencanaan pelasanaan PKPB-DV, komunikasi, informasi dan pelatihan, fasilitas, mentoring dan evaluasi, informasi, bimbingan/pelatihan dan monitoring. 


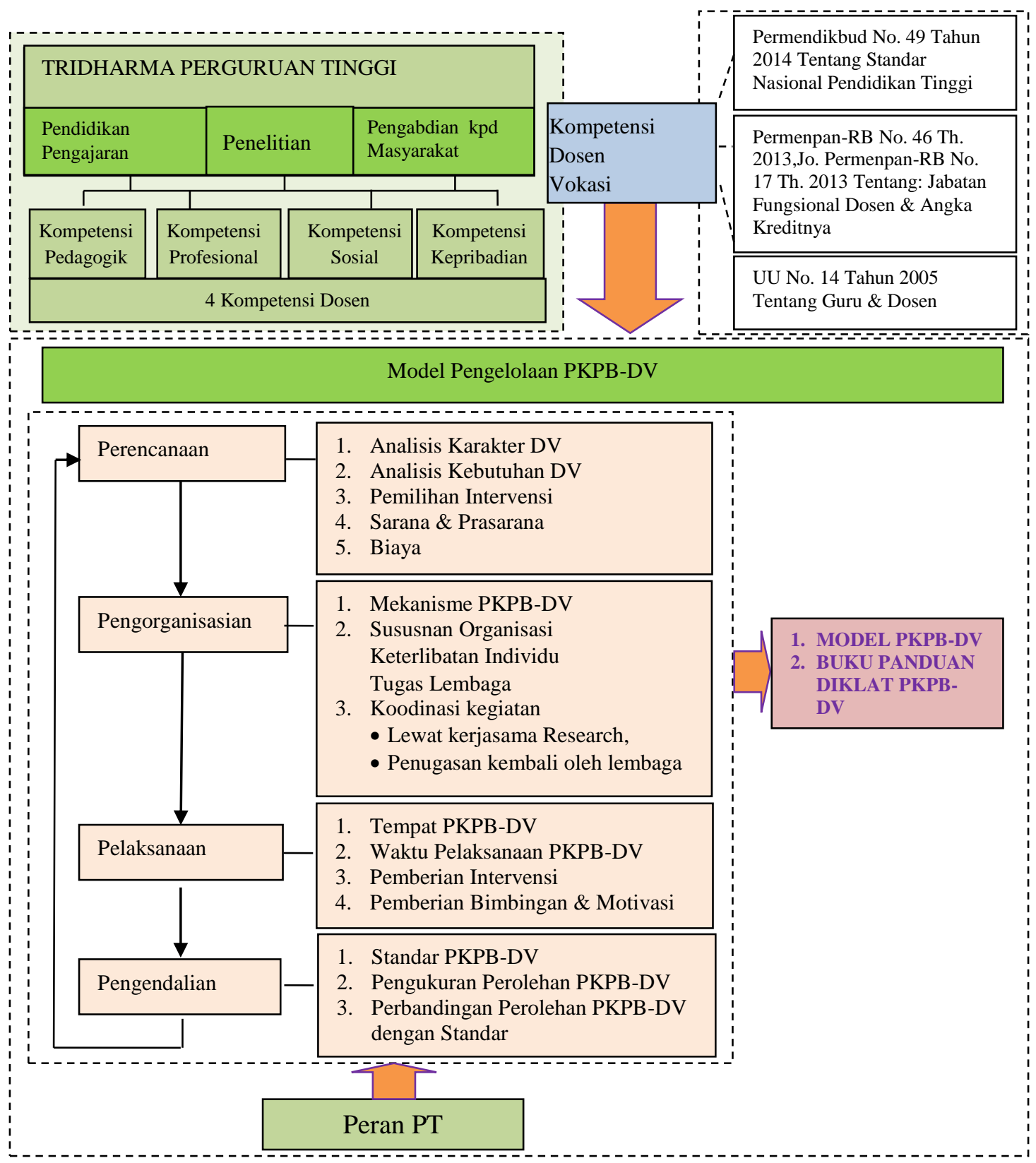

Gambar 3. Model Hipotetik PKPB-DV

Komponen model PKPB-DV mencakup perencanaan, pengorganisasian, pelaksanaan dan pengendalian. Setiap komponen diuraikan dalam isi model sebagai berikut: (1) Perencanaan, terinformasikannya analisis karakter dan kebutuhan dosen vokasi terhadap model PKPB-DV, pemilihan intervensi, sarana dan prasarana serta biaya yang diperlukan dalam penerapan model, (2) Pengorganisasian, berisi kegiatan yang menggambarkan mekanisme PKPB-DV, susunan organisasi yang berisi keterlibatan individu dan tugas lembaga dalam pengembangan kompetensi profesional dosen, serta koordinasi kegiatan pengembangan kompetensi profesional dosen dan pe- nugasan oleh lembaga, (3) Pelaksanaan, merupakan tahap penyelenggaraan PKPB-DV, yaitu tempat pelaksanaan intervensi PKPB$\mathrm{DV}$, waktu pelaksanaan, pemberian intervensi serta pemberian bimbingan dan motivasi terhadap dosen vokasi dalam pengembangan kompetensi profesional dosen vokasi, dan (4) Pengendalian, merupakan aktivitas dari pengelola yaitu membandingkan peraturan dengan hasil pengamatan kompetensi profesional dosen vokasi, adapun kegiatan yang dilakukan adalah monitoring dengan melakukan identifikasi masalah yang ditemui dosen vokasi dalam pengembangan kompetensi profesionalnya setelah diaplikasikannya model. 


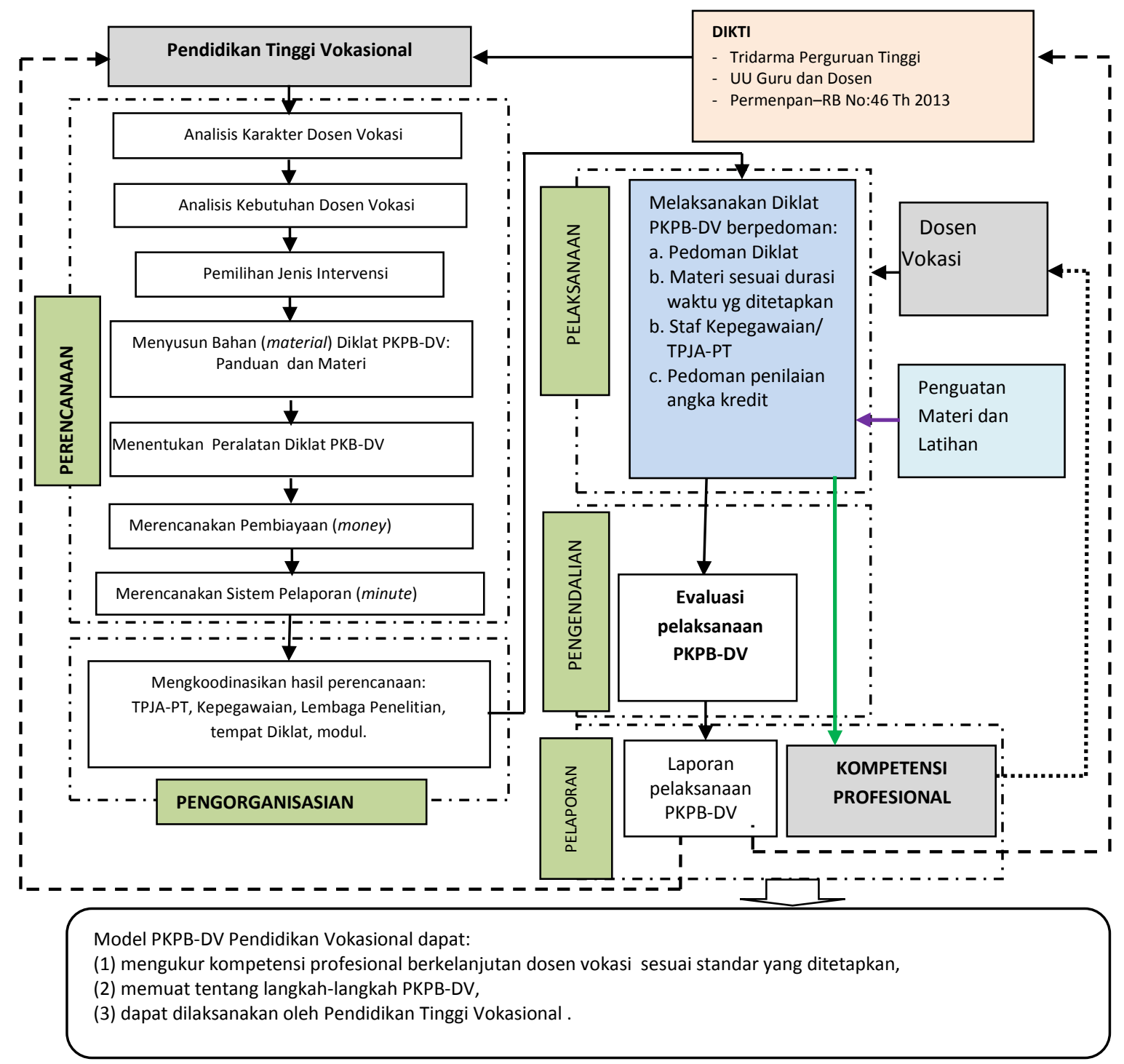

Gambar 4. Produk Pengembangan Model PKPB-DV

Tabel 1. Spesifikasi Model PKPB-DV dalam FGD I

\begin{tabular}{|c|c|c|c|c|c|c|}
\hline \multirow{2}{*}{ No } & \multirow{2}{*}{ Spesifikasi Model } & \multirow{2}{*}{ Indikator Spesifikasi } & \multicolumn{4}{|c|}{ Tingkat Penilaian } \\
\hline & & & SP & $\mathrm{P}$ & KP & TP \\
\hline \multirow[t]{3}{*}{1.} & \multirow{3}{*}{$\begin{array}{l}\text { Struktur /Elemen } \\
\text { model }\end{array}$} & Kejelasan analisis kebutuhan untuk dosen vokasi & 2 & 1 & 0 & 0 \\
\hline & & Kejelasan analisis kebutuhan untuk pimpinan PT & 2 & 1 & 0 & 0 \\
\hline & & Kejelasan analisis kebutuhan untuk bagian kepegawaian & 2 & 1 & 0 & 0 \\
\hline \multirow[t]{6}{*}{2.} & Karakter model & Adanya sintaks & 3 & 0 & 0 & 0 \\
\hline & & Adanya sistem sosial & 3 & 0 & 0 & 0 \\
\hline & & Adanya prinsip reaksi & 2 & 1 & 0 & 0 \\
\hline & & Adanya sistem pendukung & 2 & 1 & 0 & 0 \\
\hline & & Adanya dampak utama & 3 & 0 & 0 & 0 \\
\hline & & Adanya dampak pengiring & 3 & 0 & 0 & 0 \\
\hline \multirow[t]{3}{*}{3.} & Konten Model & Komponen model hirarkis & 3 & 0 & 0 & 0 \\
\hline & & Isi model mencerminkan komponen model & 3 & 0 & 0 & 0 \\
\hline & & Sasaran model sesuai dengan tujuan pembentukan model & 2 & 1 & 0 & 0 \\
\hline \multicolumn{2}{|c|}{ Jumlah } & & 30 & 6 & 0 & 0 \\
\hline
\end{tabular}

Keterangan: $\mathrm{SP}=$ Sangat Penting, $\mathrm{P}=$ Penting, $\mathrm{KP}=$ KurangPenting, $\mathrm{TP}=$ TidakPenting 
Tabel 2. Spesifikasi Model PKPB-DV dalam FGD II

\begin{tabular}{|c|c|c|c|c|c|c|}
\hline \multirow{2}{*}{ No } & \multirow{2}{*}{ Spesifikasi Model } & \multirow{2}{*}{ Indikator Spesifikasi } & \multicolumn{4}{|c|}{ Tingkat Penilaian } \\
\hline & & & SP & $\mathrm{P}$ & $\mathrm{KP}$ & $\mathrm{TP}$ \\
\hline \multirow[t]{3}{*}{1.} & \multirow{3}{*}{$\begin{array}{l}\text { Struktur/Elemen } \\
\text { model }\end{array}$} & Kejelasan analisis kebutuhan untuk dosen vokasi & 7 & 1 & 1 & 0 \\
\hline & & Kejelasan analisis kebutuhan untuk pimpinan $\mathrm{PT}$ & 8 & 1 & 0 & 0 \\
\hline & & Kejelasan analisis kebutuhan untuk bagian kepegawaian & 7 & 2 & 0 & 0 \\
\hline \multirow[t]{6}{*}{2.} & \multirow[t]{6}{*}{ Karakter model } & Adanya sintaks & 7 & 2 & 0 & 0 \\
\hline & & Adanya sistem social & 7 & 2 & 0 & 0 \\
\hline & & Adanya prinsip reaksi & 7 & 2 & 0 & 0 \\
\hline & & Adanya sistem pendukung & 7 & 1 & 1 & 0 \\
\hline & & Adanya dampak utama & 9 & 0 & 0 & 0 \\
\hline & & Adanya dampak pengiring & 7 & 2 & 0 & 0 \\
\hline \multirow[t]{3}{*}{3.} & \multirow[t]{3}{*}{ Konten Model } & Komponen model hirarkis & 8 & 1 & 0 & 0 \\
\hline & & Isi model mencerminkan komponen model & 6 & 3 & 0 & 0 \\
\hline & & Sasaran model sesuai dengan tujuan pembentukan model & 7 & 2 & 0 & 0 \\
\hline \multicolumn{3}{|c|}{ Jumlah } & 87 & 19 & 0 & 0 \\
\hline
\end{tabular}

Keterangan: $\mathrm{SP}=$ Sangat Penting, $\mathrm{P}=$ Penting, $\mathrm{KP}=$ KurangPenting, $\mathrm{TP}=$ TidakPenting

Evaluasi proses diklat, yang dilaksanakan bersamaan dengan proses diklat dengan tujuan agar dosen vokasi dapat mengembangkan kompetensinya sesuai dengan aturan yang berlaku. Evaluasi hasil, merupakan kegiatan membandingkan kinerja dosen dalam tridarma perguruan tinggi dengan standar yang ada sesuai dengan peraturan yang berlaku.

Sasaran model PKPB-DV adalah perilaku dosen dan perilaku pengelola program dalam rangka mengelola pengembangan kompetensi profesional berkelanjutan dosen vokasi di perguruan tingginya.

Gambar 4 adalah pengembangan model setelah mendapatkan masukan dalam FGD II. Untuk menerapkan model diperlulan buku panduan diklat, merupakan acuan dalam pelaksanaan Model PKPB-DV yang dipakai oleh pengelola. Faktor keberhasilan dalam penyelenggaraan PKPB-DV adalah adanya konsep utama yang jelas dan harus dimengerti oleh para pelaksana di lapangan yang dituangkan dalam buku panduan diklat. Diklat model PKPB-DV dilaksanakan di perguruan tinggi vokasional masing-masing, disinergikan dan disesuaikan dengan program dan fasilitas yang ada di setiap pendidikan tinggi yang memiliki program pendidikan vokasional.

Spesifikasi model PKPB-DV yaitu: (1) melibatkan pihak kepegawaian dan pimpinan perguruan tinggi/ TPJA vokasional dengan penuh komitmen, terpadu dan terintegrasi dengan program-program lainnya, (2) komitmen artinya diperlukan sikap dengan penuh tang- gungjawab dalam pelaksanaan model PKPB$\mathrm{DV}$, terutama dari pengelola dalam penerapan langkah-langkah pengembangan kompetensi profesional berkelajutan dosen vokasi, (3) terpadu artinya penyelenggaraan model PKPBDV diselenggarakan di tengah-tengah kalender kegiatan pelaksanaan perkuliahan, (4) pengelola model yaitu unsur kepegawaian memiliki kualifikasi tertentu dalam mengaplikasikannya baik sebagai pendamping, pembimbing dan motivator, (5) model mampu menerima berbagai karakter dosen vokasi, (6) capaian model adalah pengembangan kompetensi profesional dosen vokasi yang berkelanjutan dan merupakan model unggul perguruan tinggi dalam pengelolaan dosen vokasi, dan (7) evaluasi capaian hasil kompetensi profesional berkelanjutan dosen vokasi yang dilaksanakan secara kontinyu.

Penilaian spesifikasi PKPB-DV pada FGD I dan FGD II ditampilkan secara lengkap pada Tabel 2. Tabel 1 menyajikan hasil deskripsi bahwa hasil FGD I yang melibatkan tiga pakar, yaitu satu dari dosen vokasi, satu dari pimpinan/TPJA dan satu dari bagian kepegawaian pendidikan tinggi, sebagian besar berada pada kategori baik sekali $(83,33 \%)$ pada aspek struktur/elemen model, karakter model dan isi model.

Tabel 2 menunjukkan bahwa hasil FGD II yang melibatkan sembilan pakar, yaitu tiga dari dosen vokasi, tiga dari pimpinan/TPJA dan tiga dari kepegawaian pendidikan tinggi vokasional, sebagian besar berada pada 
kategori $80,55 \%$ atau baik sekali pada aspek struktur/elemen model, karakter model dan konten model.

Model yang telah dihasilkan pada tahap pengembangan model, selanjutkan dilakukan validasi ahli dan pengguna pada FGD III. Ahli yang dimaksud adalah pakar pendidikan vokasional, sedangkan pengguna adalah pimpinan perguruan tinggi/TPJA dan bagian kepegawaian.

Tahapan ini dilakukan untuk melihat kemungkinan keterlaksanaan model (model final) seperti yang terdapat pada Gambar 5 . Hasil analisis FGD seperti yang dijelaskan di Tabel 3 yang mendeskripsikan bahwa hasil FGD III yang melibatkan 16 pakar, yaitu enam dari dosen vokasi, enam dari pimpinan dan empat dari kepegawaian pendidikan tinggi vokasional, sebagian besar berada pada kategori $81,25 \%$ atau baik sekali pada aspek struktur/ elemen model, karakter model dan konten model.

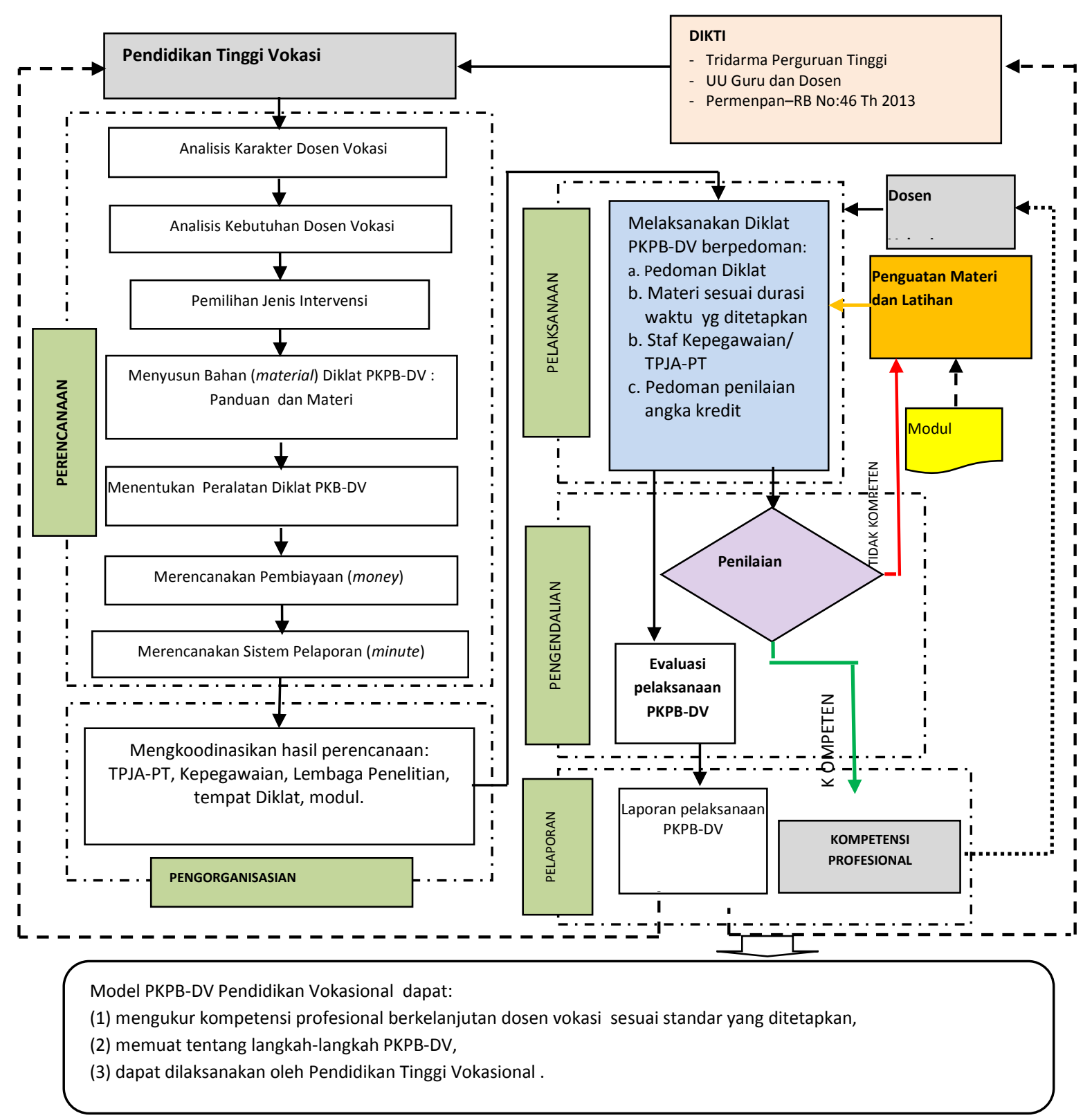

Gambar 5. Model Final PKPB-DV 
Tabel 3. Hasil Analisis Spesifikasi Model PKPB-DV dalam FGD III

\begin{tabular}{|c|c|c|c|c|c|c|}
\hline \multirow{2}{*}{ No } & \multirow{2}{*}{ Spesifikasi Model } & \multirow{2}{*}{ Indikator Spesifikasi } & \multicolumn{4}{|c|}{ Tingkat Penilaian } \\
\hline & & & SP & $\mathrm{P}$ & KP & $\mathrm{TP}$ \\
\hline \multirow[t]{3}{*}{1.} & \multirow{3}{*}{$\begin{array}{l}\text { Struktur/Elemen } \\
\text { model }\end{array}$} & Kejelasan analisis kebutuhan untuk dosen vokasi & 12 & 2 & 2 & 0 \\
\hline & & Kejelasan analisiskebutuhan untuk pimpinan PT & 12 & 3 & 1 & 0 \\
\hline & & $\begin{array}{l}\text { Kejelasan analisis kebutuhan untuk bagian } \\
\text { kepegawaian }\end{array}$ & 15 & 1 & 0 & 0 \\
\hline \multirow[t]{6}{*}{2.} & Karakter model & Adanya sintaks & 14 & 2 & 0 & 0 \\
\hline & & Adanya sistem social & 12 & 2 & 2 & 0 \\
\hline & & Adanya prinsip reaksi & 14 & 2 & 0 & 0 \\
\hline & & Adanya sistem pendukung & 14 & 1 & 1 & 0 \\
\hline & & Adanya dampak utama & 15 & 0 & 1 & 0 \\
\hline & & Adanya dampak pengiring & 10 & 3 & 3 & 0 \\
\hline \multirow[t]{4}{*}{3.} & Konten Model & Komponen model hirarkis & 10 & 4 & 2 & 0 \\
\hline & & Isi model mencerminkan komponen model & 16 & 0 & 0 & 0 \\
\hline & & Sasaran model sesuai dengan tujuan pembentukan model & 12 & 1 & 3 & 0 \\
\hline & & Jumlah & 156 & 28 & 17 & 0 \\
\hline
\end{tabular}

Keterangan: $\mathrm{SP}=$ Sangat Penting, $\mathrm{P}=$ Penting, $\mathrm{KP}=$ Kurang Penting, $\mathrm{TP}=$ Tidak Penting

Produk dari hasil ini adalah model pengembangan kompetensi profesional berkelanjutan untuk dosen vokasi pada pendidikan vokasional di Lampung. Dengan mempertimbangkan berbagai prosedur dan proses yang telah dilaksanakan, maka model ini diberi nama model "Pengembangan Kompetensi Profesional Berkelanjutan Dosen Vokasi (PKPB-DV)", dengan alasan bahwa pengembangan kompetensi profesional dosen vokasi akan terlaksana secara berkelanjutan dan memotivasi dosen vokasi untuk melaksanakan tugasnya yaitu tridharma perguruan tinggi baik pengajaran/ pendidikan, penelitian dan pengabdian kepada masyarakat dengan maksimal sehingga terjadi peningkatan 4 kompetensi baik profesional, pedagogik, sosial, dan kepribadian. Dengan demikian, dapat dipadukan antara kegiatan tridarma perguruan tinggi dengan 4 kompetensi dosen.

Model dengan nama "Pengembangan Kompetensi Profesional Berkelanjutan Dosen Vokasi (PKPB-DV)" memiliki beberapa keunggulan, yaitu: (1) adanya perencanaan yang sistematis dari pihak kepegawaian terhadap pengembangan kompetensi dosen vokasi secara berkelanjutan, (2) adanya pengkoordinasian yang sistematis di dalam pengembangan kompetensi dosen vokasi secara berkelanjutan, (3) adanya petunjuk pelaksanaan yang rinci, (4) adanya pengendalian terhadap pelaksanaan model, dan (5) adanya evaluasi yang operasional.

Aspek yang harus dipenuhi model adalah: (1) diklat disesuaikan dengan program-program tridarma perguruan tinggi dosen vokasi, (2) dibentuk kelompok kecil 2-3 orang baik dalam proses diklat dan tindak lanjut diklat sebagai wadah dosen vokasi untuk melakukan penelitian dan pengabdian kelompok dan tim mengajar, (3) diklat dapat dilaksanakan dalam ruang lingkup program studi atau jurusan, dan (4) tersedianya buku panduan diklat sebagai acuan penyelenggaraan model PKPB-DV (sebagai produk terpisah dari penelitian ini).

Hasil yang didapatkan dalam uji analisis model adalah bahwa secara prinsip, semua pakar setuju terhadap model sesuai yang direncanakan dan panduan yang sudah disusun. Namun, ada beberapa hal yang harus diperhitungkan dan menjadi bahan perbaikan/ pertimbangan yaitu: (1) yang terukur dalam kegiatan tridarma perguruan tinggi hanya aspek pengajaran/ pendidikan, (2) memerlukan waktu yang cukup lama untuk mengukur aspek penelitian, pengabdian dan penunjang dalam kegiatan tridharma perguruan tinggi, (3) responden dosen vokasi yang memiliki kompetensi tingkat profesional berbeda-beda, yang membawa konsekuensi kesulitan dalam memberikan pembimbingan berbeda, (4) pem- 
bimbingan/pendampingan/mentoring dituntut dengan pendekatan belajar andragogi mengingat dosen vokasi sudah bekerja dan dari sisi usia sudah dewasa, dan (5) masalah fasilitas teknologi dan informasi yang dimiliki dosen vokasi, dapat dimanfaatkan dengan baik jika dosen disiplin dan memiliki kompetensi untuk mempergunakannya, karena banyak tawaran hibah penelitian, pengabdian, dan unsur penunjang lainnya, bahkan pendidikan yang harus diakses dari internet sehingga semua dosen vokasi memperoleh manfaat sebesarbesarnya dari PKPB-DV.

Dari berbagai masalah dalam uji analisis model diambil suatu langkah penyelesaian sebagi berikut: (1) kepegawaian di dalam membuat perencanaan pengembangan kompetensi profesional dosen harus memperhatikan karakteristik setiap dosen vokasi, dilihat dari usia, kepangkatan dan lain-lain, sehingga dalam melakukan kegiatan berikutnya yaitu pengorganisasian, pelaksanaan dan pengendalian tidak mengalami hambatan yang berarti, (2) waktu pendidikan dan pelatihan menyesuaikan dengan waktu pengusulan program penelitian dan pengabdian kepada masyarakat, dan biasanya terjadi di akhir bulan Desember atau awal bulan januari, dan (3) karena diklat dilaksanakan dengan prinsip andragogi, maka tindak lanjutnya yaitu pembimbingan baik dari segi pembimbing dan waktu disesuaiakan dengan masing-masing dosen vokasi. Dengan prinsip ini, pembimbingan dilaksanakan menyesuaikan dengan target kompetensi profesional masing-masing dosen vokasi. Fungsi pembimbing yaitu dosen senior lebih sebagai teman diskusi dan mitra belajar, pembelajaran dapat dilakukan secara mandiri atau dalam kelompok kecil.

\section{SIMPULAN DAN SARAN}

\section{Simpulan}

Model pengembangan kompetensi berkelanjutan memiliki tiga unsur yaitu: (1) perencanaan berisi analisis karakter dosen vokasi, analisis kebutuhan dosen vokasi, pemilihan intervensi sarana, prasarana dan biaya, (2) pengorganisasian berisi mekanisme PKPB-DV, susunan organisasi mencakup keterlibatan individu dan tugas lembaga, koordinasi kegiatan mencakup kerjasama research dan penugasan oleh lembaga, (3) pelaksanaan meliputi tempat PKPB-DV, waktu pelaksanaan PKPB-DV, pemberian intervensi, pemberian bimbingan dan motivasi, dan (4) pengendalian yang berisi standar PKPB-DV.

\section{Saran}

Saran pemanfaatan model ini adalah: (a) penerapan model dapat diterapkan pada perguruan tinggi vokasional dan perguruan tinggi pada umumnya. Karena semua dosen pada hakikatnya mempunyai kebutuhan yang sama yaitu memiliki empat kompetensi dan dapat melaksanakan tridharma perguruan tinggi dengan maksimal; (b) capaian model penyelenggaraan PKPB-DV bersifat terminal destination bukan final destination, artinya model ini masih perlu langkah pengembangan dan pengujian lain dengan melibatkan perguruan tinggi vokasional dan perguruan tinggi non-vokasional lainnya; (c) perlunya penelitian sejenis pada perguruan tinggi vokasional lain.

Diseminasi diperlukan, karena model ini masih perlu dikembangkan, terutama penyempurnaan buku panduan diklat dan penerapan model di perguruan tinggi vokasional lain yang masih relatif baru. Luaran lainnya seperti kompetensi sosial dan kepribadian serta dharma penelitian, pengabdian dan unsur penunjang lainnya perlu diukur, apakah juga meningkat. Desain diklat perlu ditata kembali sehingga benar-benar sesuai dengan karakter dosen vokasi, dengan demikian isi penelitian, pengabdian dan unsur penunjang benar-benar bernuansa vokasional. Begitu juga pelaksanaan pengajaran/ pendidikan agar benar-benar mengutamakan praktik yang semuanya mengarah pada keterampilan vokasional. Beberapa upaya pemberdayaan yang masih sangat diperlukan antara lain peningkatan kemampuan kepegawaian dalam pengelolaan diklat, penciptaan budaya organisasi atau lembaga yang kondusif dalam aspek collegial relationship; peningkatan kualitas pelayanan yang melibatkan semua stakeholder. Melalui berbagai upaya tersebut diharapkan penyelenggaraan PKPB-DVdapat menunjukkan hasil optimal.

\section{DAFTAR PUSTAKA}

Bolam, R. (2006). Emerging policy trends: some implications for continuing professional development. Retrieved 
July 2, 2014, from http://www.tandfonline.com/loi/rjie19

Depdiknas. Undang-Undang No. 14 Tahun 2005 tentang Guru dan Dosen (2005). Jakarta.

Hegde, P. (2013). Faculty development trends in medical education: a review. south east asian. Journal of Medical Education, 7(2), 11-16.

Hoekstra, A., \& Crocker, J. R. (2015). Design, implementation, and evaluation of an ePortfolio approach to support faculty development in vocational education. Studies in Educational Evaluation, 46, 61-73.

https://doi.org/http://dx.doi.org/10.1016 /j.stueduc.2015.03.007

Inggalls, J. (1973). A trainer guide to andragogy it is concept, experience and application. Washington Departemen of Health Education and Welfare.

Jackson, A. (2011). Action technologies: supporting continuing professional development. Retrieved July 2, 2014, from

http://www.tandfonline.com/loi/rpce20

Kenyon, C., \& Hase, S. (2010). Andragogy and heutagogy in postgraduate work. In T. Kerry (Ed.), Meeting the challenges of change in postgraduate higher education. London: Continuum Press.

Knowles, M. (1970). Informal adult education: a guide for administrator, leader and teachers. New York: Association Press.

Malmqvist, J., Gunnarsoon, S., \& Vigild, M. E. (2008). Faculty professional competence development programs comparing approaches from universities. In Proceeding sof the $4^{\text {th }}$ International CDIO Conference. Gent, Belgium: Hooge School Gent.

Saraka. (2001). Model belajar swaarah dalam pengembangan sikap mental wiraswasta. Bandung: PPS-UPI.

Srinivasan, L. (1977). Perspectives on nonformal adult learning: functional education for individual, community and national development. Connecticut Prentice Hall.

Sudijono, A. (2009). Pengantar statistik pendidikan. Jakarta: Rajawali Pers.

Sugiyono. (2010). Metode penelitian pendidikan, Pendekatan kuantitatif, kualitatif dan $R \& D$. Bandung: Alfabeta.

UNESCO. (1988). Continuing education: new policies and directions. Bangkok:

UNESCO principal Regional Office for Asia and the Pacific.

Wenrich, R. C., \& Wenrich, J. W. (1974). Leadership in administration of vocational and technical education. Ohio: Charles E.Merrill Publishing Company, a Bell \& Howell Company Columbus. 